\title{
The Dimensions of the Mobile Visitor Experience: Thinking beyond the Technology Design
}

Marco Mason, School of Museum Studies, University of Leicester, Leicester, UK; Program in
Science, Technology, and Society, Massachusetts Institute of Technology, Cambridge, MA, USA

Abstract: In the Twenty-first century, museums' mobile digital technology has a prominent role in communication and interpretation thanks to its characteristics of multimodality, handiness, ubiquity, accessibility, and social networking. Digital technology had been a central topic of design discourse in museums up until the recent years. In recent years the attention has shifted from technology to visitor experience. Nowadays the innovative character of mobile devices depends not so much on technology per se as on socio-technical system that now, more than ever before, put visitor's needs and museum environment at the core of the design. Designing mobile apps with the visitor experience as an explicit outcome means looking beyond functionality: we should take into account visitors' expectations, motivations, and behaviors, above and beyond interface usability, and then extend this understanding to the context of the use of the device and to the whole experience of the visit. Any design effort should go in the direction of integrating all of these dimensions. This paper's contribution comes from answering the following question: what are the "dimensions of the context" of mobilemedia-enhanced visitor experience? In investigating recent studies and analyzing recent projects on mobile media for museums we have classified three main domains - museum, visitor, and mobile technology. From these domains we have identified fundamental dimensions that can help designers and museum practitioners to better understand the context in which visitors use a mobile app and, in turn, enable them to make more informed design decisions.

Keywords: User-centered Design, Museum, Visitor Experience, Mobile App

\section{Introduction}

$\mathrm{D}$ igital technology (including mobile devices) has become a major topic in museum design. This technology places visitor's needs and museum objectives at the core of the design process. Designing digital technology for museums with the visitor experience as an explicit outcome means looking beyond functionality: we should take into account visitors' expectations, motivations, and behavior, visitors' interactions with mobile interface buttons (usability), and then extend this understanding to other factors of the whole context of use. Any design effort should go in the direction of carefully considering and integrating all of these factors in digital media. Factors that need to be considered include content and interpretation aspects, the physical orientation within the museum environment, multimodal and interactive features of mobile devices, and so on. In this paper, I refer to these "factors" as "dimensions of the context."

Wigelius and Väätäjä (2009) conducted a comprehensive review of many studies "in the areas of Computer- Supported Cooperative Work (CSCW), ubiquitous and context-aware computing, and user experience as well as in mobile work." What clearly emerges from their research is the importance of understanding the socio-technical context of the mobile app and how its dimensions affect the user experience. According to the authors, "if the context has not been identified and understood, the use of the mobile systems may fail or the user experience may suffer."

Understanding the "dimensions of the context" is important for mobile media designers, since bringing them into the design process from the early phase enables them to make more informed design decisions during the development of the digital device.

The aim of this paper is to describe contextual dimensions of mobile-base user experience for the specific context of museums.

Before going further, it is important to detail what the term user experience refers to and how it applies to museum-related research context. Only after a more clear definition can we better delineate what the "dimensions of context" are in mobile media for museums and why considering them is so important for designing mobile apps that enhance the visitor experience. 
The user experience is a term for describing the overall experience and satisfaction a user has, as well as what $\mathrm{s} /$ he feels, when using any product or system, whether a car, a website or (as in our case) a mobile app for museums.

Donald Norman ${ }^{1}$, a cognitive science researcher who was also one of the first designers to describe the importance of user-centered design, coined the term user experience. He stated the need for designers to study and evaluate how users feel about a system, looking at such things as ease of use, perception of the value of the system, utility, efficiency in performing tasks, the influence of the surrounded environment (physical, virtual, and social), and so on. The fact that design decisions should be based on the needs and wants of users justifies the stress we place on considering and enhancing the user experience, as it addresses user needs and their tasks within the context of use.

It clearly follows that taking an experiential approach to the design of a product needs to put user experience, including what really matters to people and what it takes to make technology more meaningful, before functionality (Hassenzahl, 2010). For example, technology alone does not determine the quality of the whole experience, because the actual mobile device is just a part of a larger complex of needs, desires, activities, and contexts (Kuniavsky, 2010).

We can extend an analogy between the user experience and our research focus by using the term "visitor experience" to describe the overall experience and degree of satisfaction a museumgoer has when $\mathrm{s} /$ he visits a museum. It is important to stress that in the distinctive context of the museum the user experience assumes its own particular meaning. In bringing concepts, definitions and knowledge about user experience design into our field of study, we must consider the particular (and exceptional) context of our research: the museum's environment, mission and objectives, its content, and its visitors.

It is clear now that in museum contexts the visitor experience does not only concern the usability of the mobile device - although this is a crucial aspect - or its aesthetic appeal, but also several other "dimensions", ranging from the conceptual accessibility of the content, to the value of the learning experience, to social interactions with other visitors, and so on. From this perspective, the design of the experience (as mediated by mobile media) is based on the holistic consideration of all these dimensions.

The analysis and interpretation of data gathered - from contextual review, observations, and interviewing designers and museum practitioners ${ }^{2}-$ resulted in the first general categorization constituted of three main domains: museum, technology (mobile device), and visitor. This partition groups "dimensions of the context" according to three recurrent central domains in user experience design. In fact, within principal user-cantered and experience design paradigms (Brown 2009, Cooper et al. 2007, Preece et al. 2011), it possible to characterize recurrent fundamental domains, which designers consider and integrate in order to: (a) give form to a product (mobile technology domain); (b) satisfy people's needs and expectation through the deployment of the product (visitor domain); and (c) pay attention to organizational strategic priorities (museum domain).

Fundamental dimensions have been identified from these three domains. These dimensions can help designers and museum practitioners to better understand the context in which visitors use a mobile app and, in turn, enable them to make more informed design decisions.

\footnotetext{
${ }^{1}$ Donald Norman uses the term in his famous book The Design of Everyday Things.

${ }^{2}$ Part of this research comes from my doctoral research titled "Designing Mobile Visitor Experience: Shifting the Focus from the Technology to the Visitor." Iuav University of Venice, faculty of Arts and Design. Supervisors: Prof. G. Anceschi and Prof. E. Arielli.
} 


\section{Technological and Infrastructural Dimensions}

\section{Mobile Technology Should Offer Seamless Experiences Across Platforms}

Hooper-Greenhill (2000) introduced the idea of "post-museum," where the exhibition is only one form of museum communication. The exhibition is then enriched by other communication means in order to suit visitor needs and stimulate interpretations of objects. This concept underlines the museum's tendency to go beyond a multi-platform museum model - where every communication channel works independently - and to think of the museum as an integrated system of communication, where different platforms work together to configure a holistic system that is greater than the sum of its parts.

Proctor (2011b) starts from a similar idea of multi-platform museum to generate her distributed network model. She explains that there is no central point in the distributed network model but rather, like the Internet, multiple media forming a network of communications (fig. 2).

Although Proctor specifies that distributed networks do not technically exist yet (at least, not in the ideal form shown in fig. 2), using her model as an inspirational metaphor allows us to view the museum as a medium formed by multiple platforms interconnected amongst themselves.

Since the world is so strongly connected today, visitors are expecting more and more to be able to use mobile devices consistently across platforms before entering in or once they are within the museum space. For example, the Museum of Modern Art's iPhone App offers visitors several possibilities to interact with the museum before even walking through their doors. They can find out what's on at the Museum, how best to plan a visit before coming, and even what audio to download from the MOMA website and then put together as a playlist to create a tour. Visitors can also explore the collection through multimedia tours or share a picture of a piece with friends3.

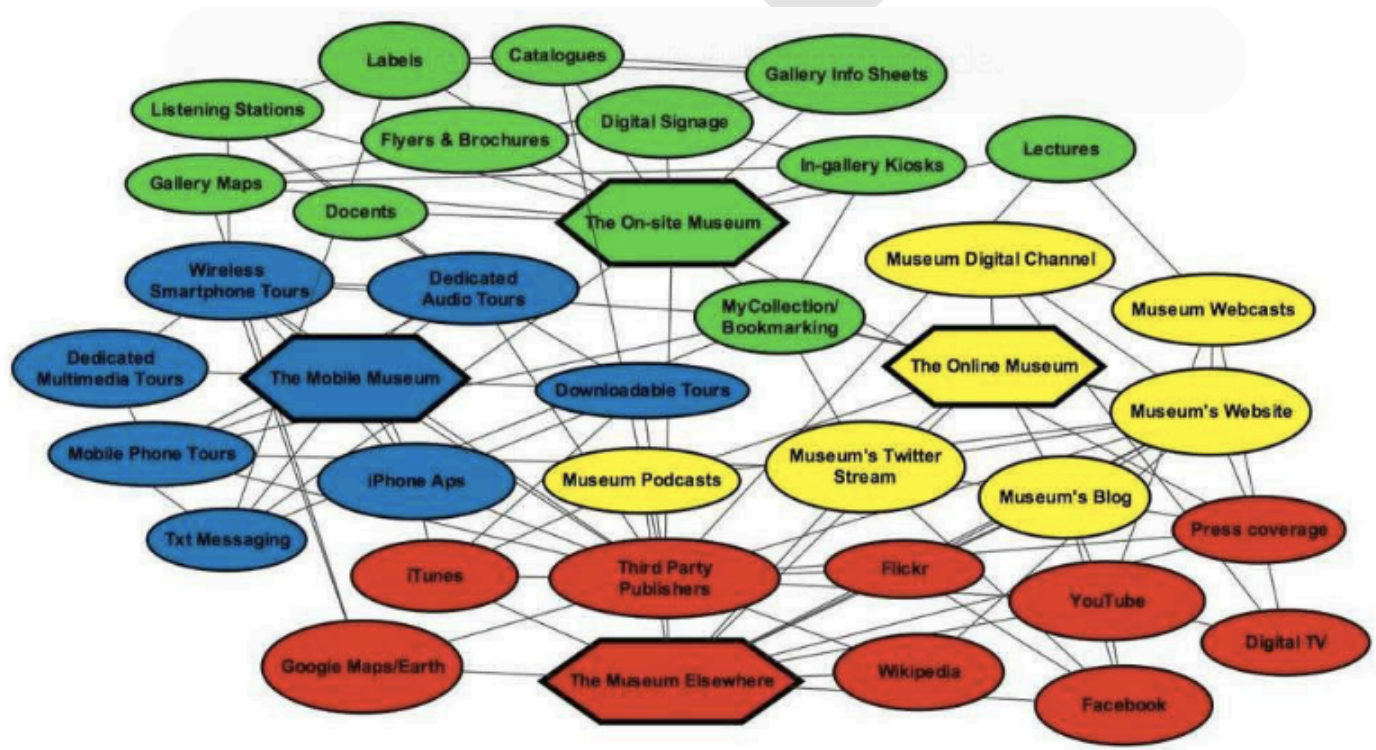

Fig. 1 - In this diagram Proctor shows how Mobile Media (Blue labels) are part of the Museum Distributed Network. Source: http://www.slideshare.net/nancyproctor/

\footnotetext{
${ }^{3}$ http://www.moma.org/explore/mobile/iphoneapp
} 


\section{Native and Web-based Apps: the Connectivity Issue}

Ted Forbes (2011) wrote an essay that clearly describes the two types of apps that it is possible to develop for museums: "device-native" and "web-based":

"Device-native apps are designed to be installed directly on to the mobile device, and are found in Apple's iTunes Store or the Android Market, for example. All of the leading smarphone operating systems provide a market where users can find apps and install them on their phones or tablets. 'Web-based' applications work inside the web browser. Rather than going to an online store to browse, download and install the application, the browser is used to navigate to a website that is optimized for use on the mobile device and offers app functionality." (Forbes, 2011)

These two types of apps both offer tremendous opportunities but, at the same time, each has its own advantages and disadvantages that, in turn, have repercussions for the visitor experience.

Native apps have long been recognized as being more powerful in terms of technical features and options. As such, they have acquired a larger market share than web-based.

Internet connectivity is a key concept that tends to "tip the scale" in favour of native apps. While mobile-specific apps do not always have to be connected to the web - even though there are several native apps that incorporate web-browsing into their functions - web-based apps must be connected to the web to transmit the content to the device. This could be a big problem if the museum does not have $\mathrm{Wi}-\mathrm{Fi}$ access or if available $\mathrm{Wi}-\mathrm{Fi}$ is slow. This limitation is common in historic buildings whose structural configurations require very expensive hardware systems to cover the connection in each room (Fantoni et al., 2011). There might be the possibility of the visitor using his/her own subscription-based coverage (which allows him/her to connect to the Internet via $3 \mathrm{G}$, for example), but these subscriptions are often either pay-per-use or subject to traffic limits. These services generally cost extra, and visitor surveys have confirmed that visitors rarely like to spend their own money to stay connected for the duration of their visit.

One possible solution is to offer visitor a free access point in a specific area of the museum. At the National Portrait Gallery in London, visitors have free access to a Wi-Fi spot in an area located before the entrance of the gallery.

While considering this main disadvantage to web-based apps, we should recognize that there are advantages offered by web-based mobile apps as well. One of the most important advantage is that web-based apps run on a mobile web browser: this allows them to be easily accessible by a variety of devices - independent of either the kind of operative system it runs on or the brand of the smartphone). For example, smARTphone tours at the Dallas Museum of Art is a web-based app available for any kind of smartphone platform such as iOS and Android4. Using a web-based app, there is nothing to download from the iTunes Store or the Android Market, nor is it necessary to install any software before beginning the visit. One may simply open the web browser and enter the application's URL (Leon, 2009; Forbes, 2011).

By contrast, native apps are proprietary and can only work on the mobile device and operating system for which it was created, making it necessary to adapt the app for each and every device and operating system that will support it.

\section{Interaction Via a (Small) Display}

This "dimension of context" concerns technical features for displaying and conveying digital content. One of the key technical characteristics of most mobile devices is the possibility they afford to interact directly via the display, without interposing keyboard buttons or a mouse. Even with the relatively small screen, the high-resolution displays available nowadays allow several possibilities for interaction with the content.

\footnotetext{
${ }^{4} \mathrm{http}: / /$ dallasmuseumofart.mobi
} 
Visitors will want to interact with the museum mobile app according to similar modalities they are accustomed to when using apps in everyday life. This means designing apps using gestures the visitor normally performs on small-screens and interface configurations which are easy to understand. Proctor, in defining Mobile Product Development Principles, states that "for quality and consistency of user experience mobile initiatives should use standard interfaces" (Proctor, 2011). She does not mean "copy-and-paste" interchangeable interfaces that are always the same, but instead a standard type of interface setting that is easily recognizable to visitors. In diminishing the difficulty for visitors to figure out how the interface works, we consequently decrease the visitor's cognitive load and thus enhance the visitor's experience. This does not imply eliminating either design creativity or originality, but finding the right balance between originality and commonly-recognised interface metaphors.

One great example of this balance is the Infinity of Nations iPhone app (fig. 2). This app offers visitors a standard and usable interface that has characteristics of originality in the interaction, information, and graphic design.
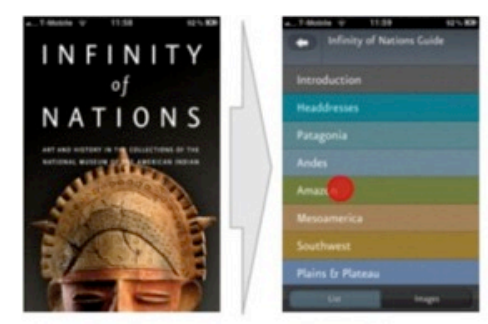

or

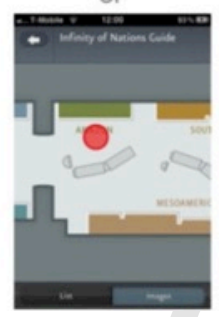

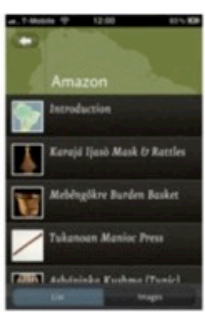

or

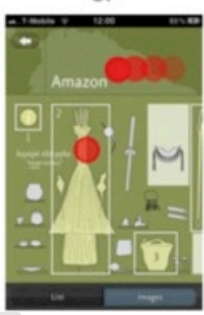

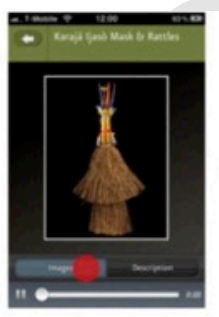

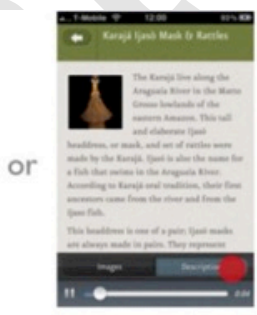

Fig. 2 - Infinity of Nations iPhone app

We have seen how "technological dimensions" affect the choice of the mobile app from museums. For example, the presence or absence of a Wi-Fi network in the museum obliges designers to opt for a Native or Web-based app.

At the same time, visitor needs, expectations and behaviors give new design challenges to museum professionals: for instance, the challenge of creating mobile apps that are, more and more, integrated with other platforms such as the web.

Finally, every day people are used to interacting with apps that one easy to use, but at the same time not trivial and useless. Visitors expect the same kind of apps when they visit museums.

It turns out that the technological dimensions should be strongly considered by designers as these factors influence many aspects, from the digital content and information structure, to interactions, to interface design.

\section{Museum Dimensions}

\section{Way Finding and Orientation Features}


One of the most important aspects that affect the visitor experience is the physical orientation. The museum mobile app should make physical orientation sufficiently clear and organizational structure comprehensible. This does not mean forcing visitors to follow a route or dictating what they should view and how they should view it. Visitors have to move through museum in an efficient manner, reducing the physical fatigue and sense of disorientation in order to avoid spending unnecessary energy and time in finding their way. To help eliminate this problem, mobile apps have recently started to include functions which indicate to visitors where places to rest can be found.

Mobile apps allow the visitor to orient him/herself during the visit by suggesting a possible itinerary and pointing the way to the next exhibit. In order to facilitate spatial navigation, recent mobile apps have adopted maps to offer directions based on the position of the visitors (fig. 3 )

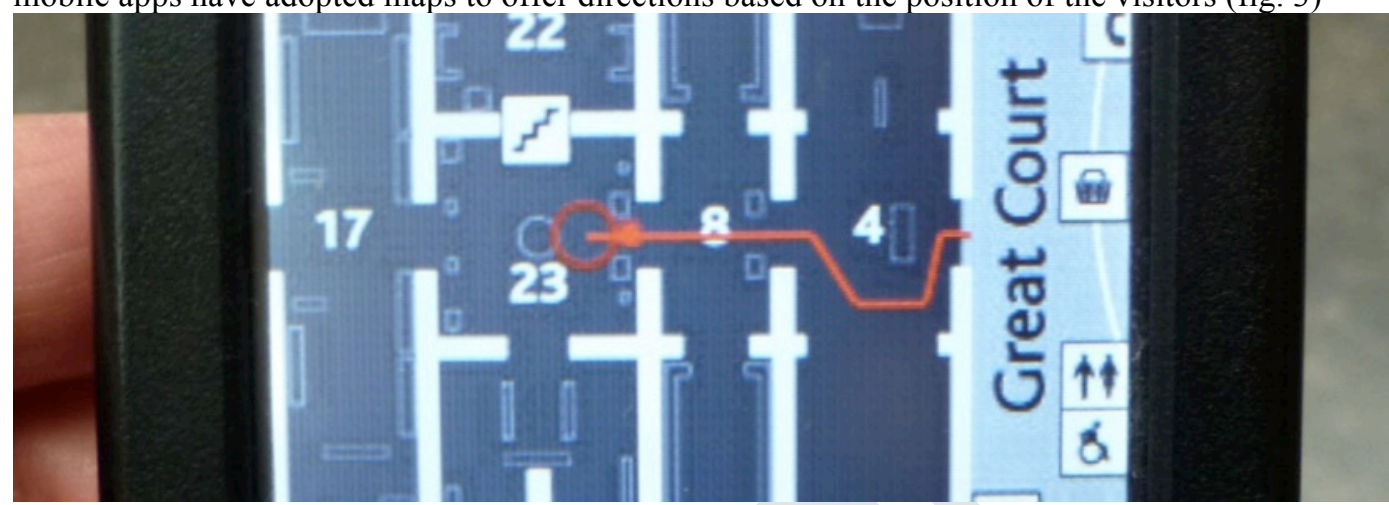

Fig. 3 -British Museum Multimedia Guide. The "Navigator Tour"

Any positioning system represents much more than just a tool by which visitors can locate where they are in the museum. Accessing the right information in the right place facilitates the semantic connection between interpretative content and the object it refers to, since visitors can be aware of their position in relation to objects displayed in an exhibition. Mobile devices may adopt three main approaches for supporting the visitor location awareness:

1. Alphanumeric, visual clue, and $Q R$ code. In this case the mobile device is used as a traditional audio guide device: the visitor need only dial the alphanumerical code associated with the exhibit onto his/her keypad (fig. 4a). The same thing might be performed with visual clues or a QR code, since the difference is only in the interaction but not in the underlying principle (fig. 4b). Although the use of mobile location-based features seems limited in this case, it is actually useful for visitors who do not have sufficient confidence with digital interactive maps and who are more fond of older, traditional devices.
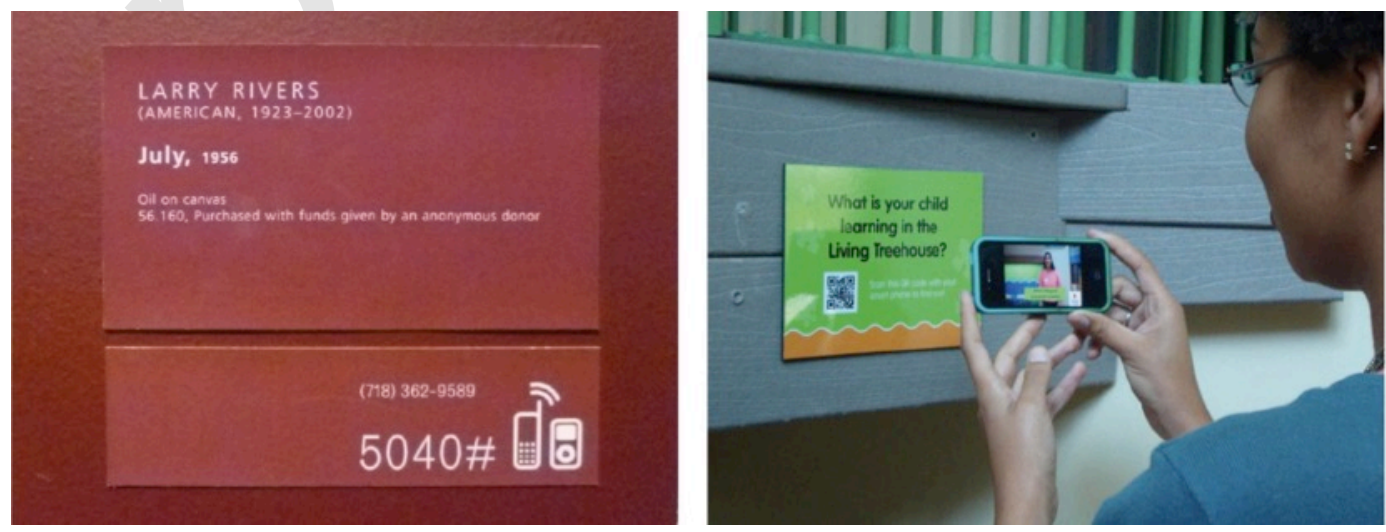

Fig. 4a, b-Alphaniumeric code and QR code. 
2. Static imagery or interactive digital map. Nearly every mobile device used in museums nowadays offers a digital map to orient visitors during the visit. This might be a simple still image that shows the museum plan, but which does not allow for any interaction (fig. 5). More advanced visual maps not only show the museum floor plan, but also give visitors the capability of interacting with the map, such as selecting markers that represent the objects on display. In this case, the map works as a multimedia page that links objects to related content. Through an interactive map, a visitor can easily recognize her/his location and determine the position of the objects near her/him that are flagged by the mobile app (see examples in fig. 6).
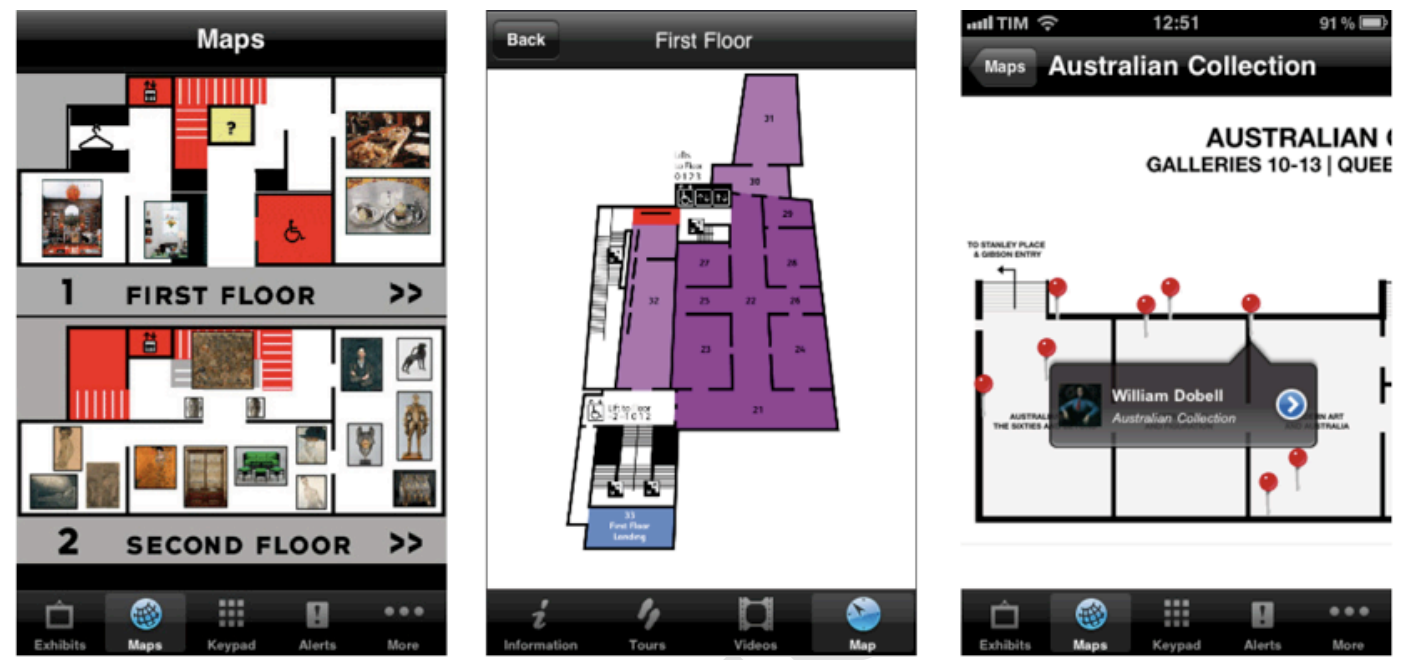

AUSTRALIAN 1 GALLERIES 10-13| QUEE

Fig. 5 - (from the left): Static map for the Lauder Collection iPhone app; static map for the NPG "Talking Guide" app; interactive map for the QAG-GoMA iPhone app.
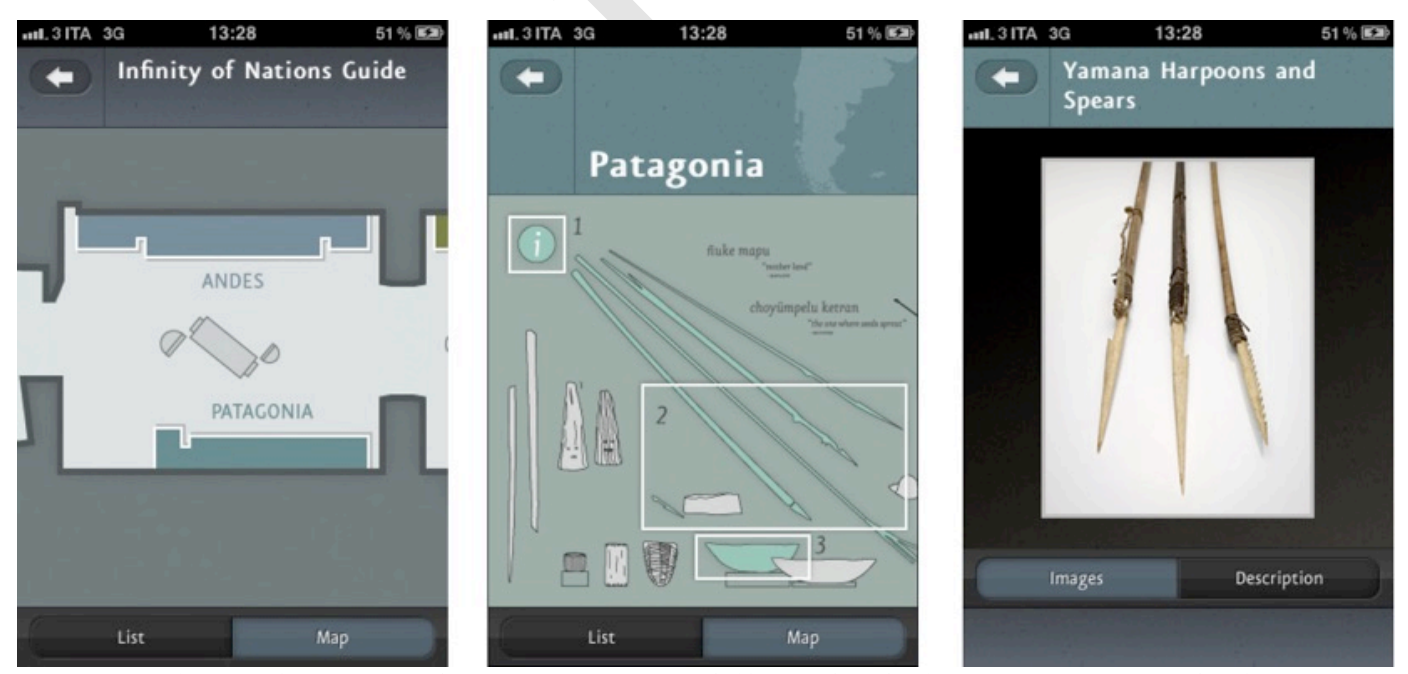

Fig. 6 - Infinity of Nations iPhone app uses two different kind of interactive maps: the former as traditional floor-map and the latter as wall-map to identify objects hung on the wall.

3. Geo-location system. Thanks to a specific Wi-Fi technology that determines the spatial location of the mobile device with reasonably good precision, it is possible for the visitor to locate where $\mathrm{s} /$ he is within the museum. More common technology such as GPS does not provide pinpoint accuracy needed for determining the position of the 
visitor with exact precision and, more crucially, does not work indoors. Wi-Fi triangulation technology offers an effective solution to these problems. The American National History Museum Explorer is one of the best examples of a mobile app that uses this technology. By using Wi-Fi triangulation, an iPhone device can position itself in the Museum with enough accuracy to display the exhibit hall in which the visitor is located (fig. 7).
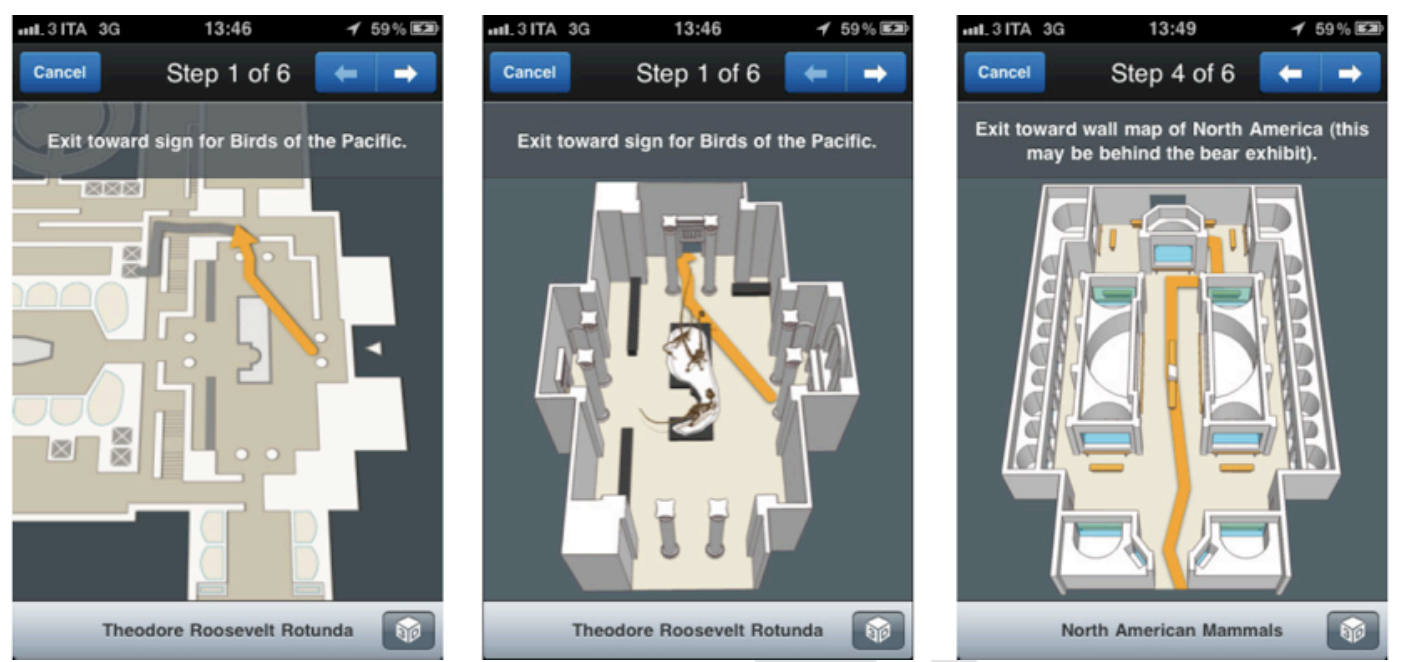

Fig. 7 - The American Museum of Natural History in NYC. In addition to familiar 2D floor plan views, 45-degree angle 3D views of each exhibit hall were created for the wayfinding system.

\section{Physical and Virtual Museum Environment}

The use of mobile apps should not be thought of only during the moments of the physical visit within the museum. It is crucial to consider the stages of a museum visit as a whole, including the pre- and post- visit as well. The mobile app must consider not only the whole visiting period and activities of the visit, but it should be well-integrated within the context of the entire visit.

Mobile apps are often designed to create continuity between pre-, post-, and actual museum visit experiences. This process is illustrated by the 'virtuous circle' as shown in figure 8 (Barry, 2006), and is intricately connected with mobile learning issues. The visitor can potentially start her/his learning experience well before the physical visit and can continue learning later, after the visit.

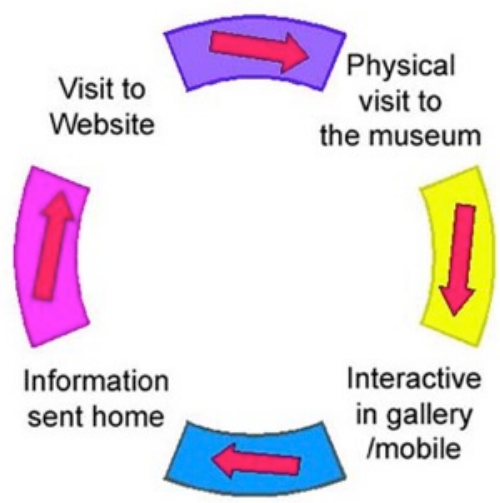

Fig. 8 - The Virtuous Circle (source: Barry, 2006) 
For instance, the multimedia mobile app DIGIT of the Dulwich Picture Gallery of London employs a system of downloading files for the museum pre-visit particularly targeted towards schoolchildren. Once they arrive at the museum, the students are given a PDA in which an itinerary chosen by their teacher has been previously downloaded. Answers to question prompts, properly saved, will be discussed as a group back in the classroom. This adaptation of mobile technology strengthens the pre-visit planning experience through the exploration of the collection and the creation of a personalized tour based on visitors' interests (fig. 9). It also strengthens the post-visit discussion by recalling images and thoughts that the students saved to their mobile devices.

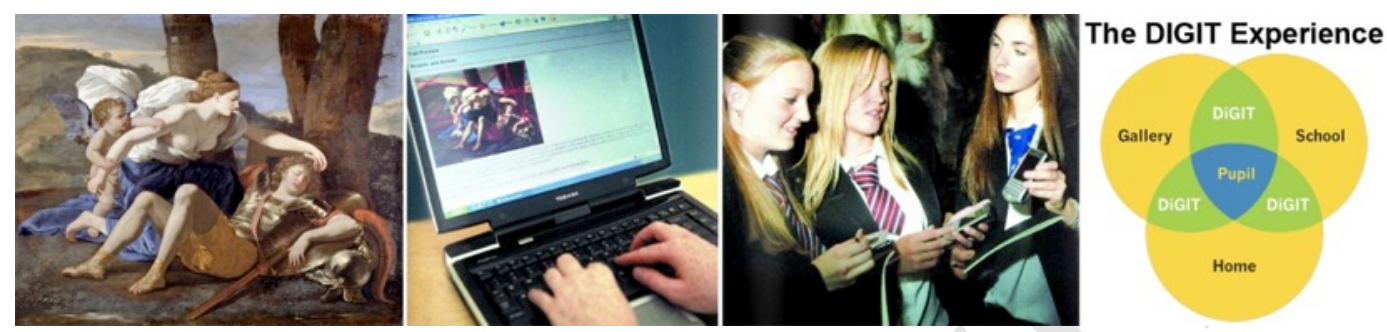

Fig. 9 - Digit at Dulwich Picture Gallery.

Source: http://issuu.com/dulwichpicturegallery/docs/digiteducation

\section{External image as a vital aspect}

Museums have to consider their external image as a vital aspect. Thus, mobile media should encourage new visitors to come to the museum. Mobile apps have great potential to reach and attract non-traditional visitors thanks to their appeal to a wide number of people (especially teenagers and youth). New audiences who normally might not be interested in more traditional interpretation resources such as audio guides may be intrigued a the idea of using their phones (Fantoni, 2008).

Museums may be interested in serving particular audiences such as families with children, people with special needs, and so on. Who their audiences are deeply influences both interpretation and design choices that they apply to content (e.g. a specific family-friendly itinerary), interactivity (e.g. functions that foster cooperation between parent and child), and to the visual interface (e.g. adopting an "engaging" graphic). For example, the Tate Modern in London is paying great attention to satisfy different targets of audience by offering visitors diverse mobile apps to explore the collection and to play art games5.

\section{Interpretation and Lifelong Learning}

Interpretation is at the heart of the museum's mission, since objects on display, especially works of art, do not have self-evident meanings (Samis, 2007). Peter Samis underlines that:

"the work of interpretation, then, is to give cognitive hooks to the hook less, and assure that these hooks are sufficiently varied so that they can successfully land in the mental fabric of a broad array of visitors. Once visitors have a framework, all kinds of sensory impressions, emotions and reflections can weave themselves into the fabric of perception." (Samis, 2007)

Thinking about a "mobile interpretation" becomes fundamental for museums that intend to adopt an effective mobile app. Creating an effective app requires integrating traditional interpretation practices within those for mobile media. Debates amongst the major museums

\footnotetext{
${ }^{5}$ See http://www.tate.org.uk/visit/tate-modern/things-to-do/mobile-apps-guides
} 
around the world have come to this conclusion: museums have access to rich resources for enhancing their own "interpretative mobile" practice (Smith, 2009; Proctor 2010).

Each museum needs to create their own careful blend in order to satisfy, but not overwhelm, visitors. Together with other "dimensions of context," the attention museums will put into adopting effective interpretation practices for their mobile apps plays a crucial role in the final result. The best practices are those designed with visitors in mind, and understanding what a particular target of audience expects and needs from the museum experience. According to Nancy Proctor, "putting audiences at the center of museums' mobile content and experience designs makes it possible to engage them through the media consumption practices and platforms that they already use outside of the museum" (Proctor, 2010).

Downe describes how the Tate Modern "puts audiences at the center" before starting new mobile projects6. Their goals in using preliminary audience research to understand: (a) what the visitor can achieve from the mobile project (through contextual and non-contextual interviews); (b) how the service needs to improve/differ from what the visitor already does (through observation, shadowing and the customer journey map); and (c) who the visitor is (through personas). Studying visitors can give museum practitioners and designers precious clues for interpretation.

Afar from being comprehensive, it can be useful to show, as examples, some practical principles to consider when engaging visitors in a meaningful experience. Interpretation seeks to use the visitor's personal context to build on pre-existing experience, skills and knowledge (Black, 2005). The visitor might be directly engaged and included by avoiding merely "talking at" them ("transmitting" notions instead "engaging" him/her), by building on his/her previous experience, skills and knowledge, and by encouraging a "critical thinking" approach. In this way, visitors can construct their own personal meaning rather than accepting outside opinions without criticism.

Moreover, interpretation emphasizes clarity of vision. It is fundamental to give the visitor an idea of "what the museum wants [him/her] to leave with" (Black, 2005). In terms of communications, mobile apps should be clear about the exhibit's intent and its parts in order to offer visitors pathways. Content should offer visitors "cognitive orientation." Visitors should also be provided with a conceptual frame of reference, such as what the exhibition is about, how it might be related to the visitor's interests, how it is organized, what the visitor can gain from it, etc.

We can also mention how sound interpretation should recognize multiple points of view. The possibility that visitors can explore several layers of content through various sound clips can give them different points of view about one artifact that come from several "voices" (fig. 10). Any object has the opportunity to be read from multiple points-of-view. For this reason, interpretation should incorporate a wide spectrum of voices and opinions from both inside and outside the institution (Proctor, 2010).

\footnotetext{
${ }^{6}$ Downe, Louise. "Defining the Design Context for a Mobile Experience." Presented at the Second Museum \& Mobile online Conference (2011), http://www.museums-mobile.org
} 

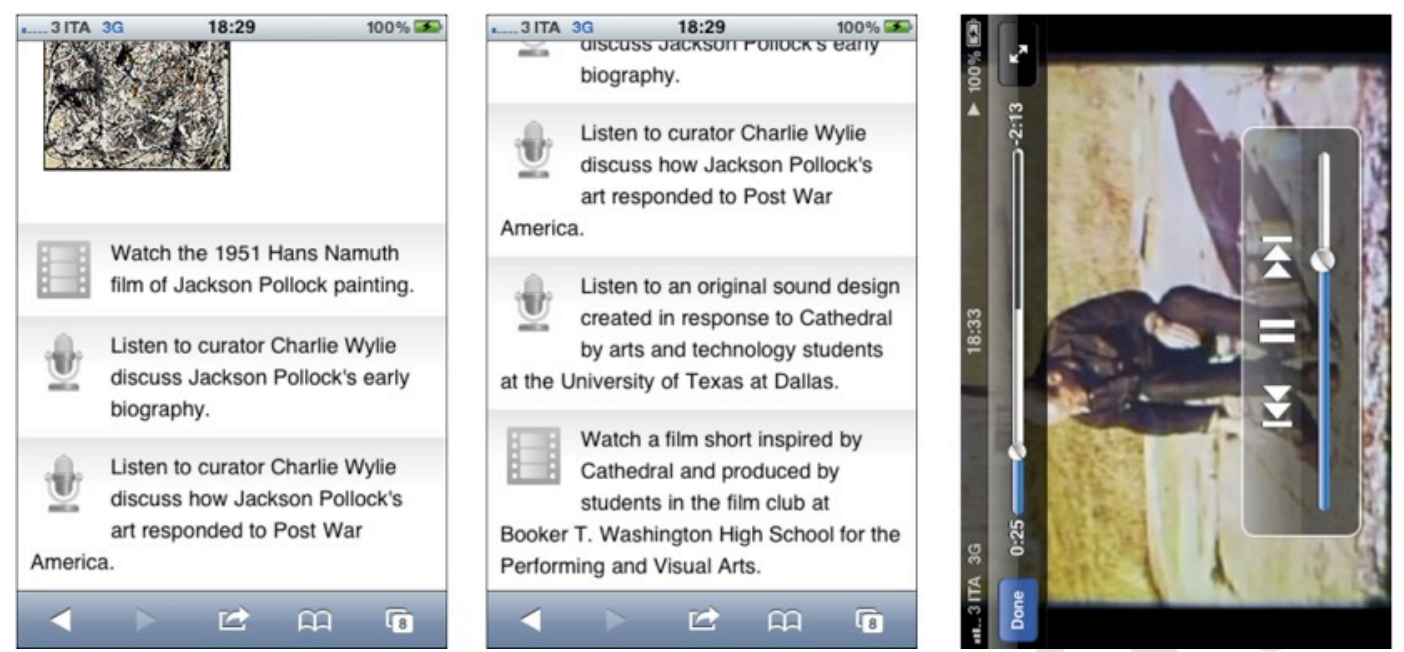

Fig. 10 - Dallas Museum of Art web-based app is a good example of how to associate several "voices" with work of art (in this case, Jackson Pollock - Cathedral)

\section{Visitors Dimensions}

\section{Need of Multimodality}

Thanks to the capability of including several kinds of content, mobile-enhanced museum experiences take great advantage from multimodality. They offer visitors engaging content, which integrates different messages and information into the museum tour experience (fig. 11, 12). Mobile apps for museums might adopt multiple source materials such as: texts, images and pictures, video interviews with curators and experts, (who can describe the exhibition or the room the visitor is in); artists (through direct or past interviews); sound (which can be very engaging, especially when it reproduces the sound of the environment where the object on display was originally placed), and $3 D$ models (for dynamically exploring an object and its components in details).

By providing different levels of interpretation through interactive participation, a mobile device can be of great support to the visitor's learning process and the creation of meaning through content.
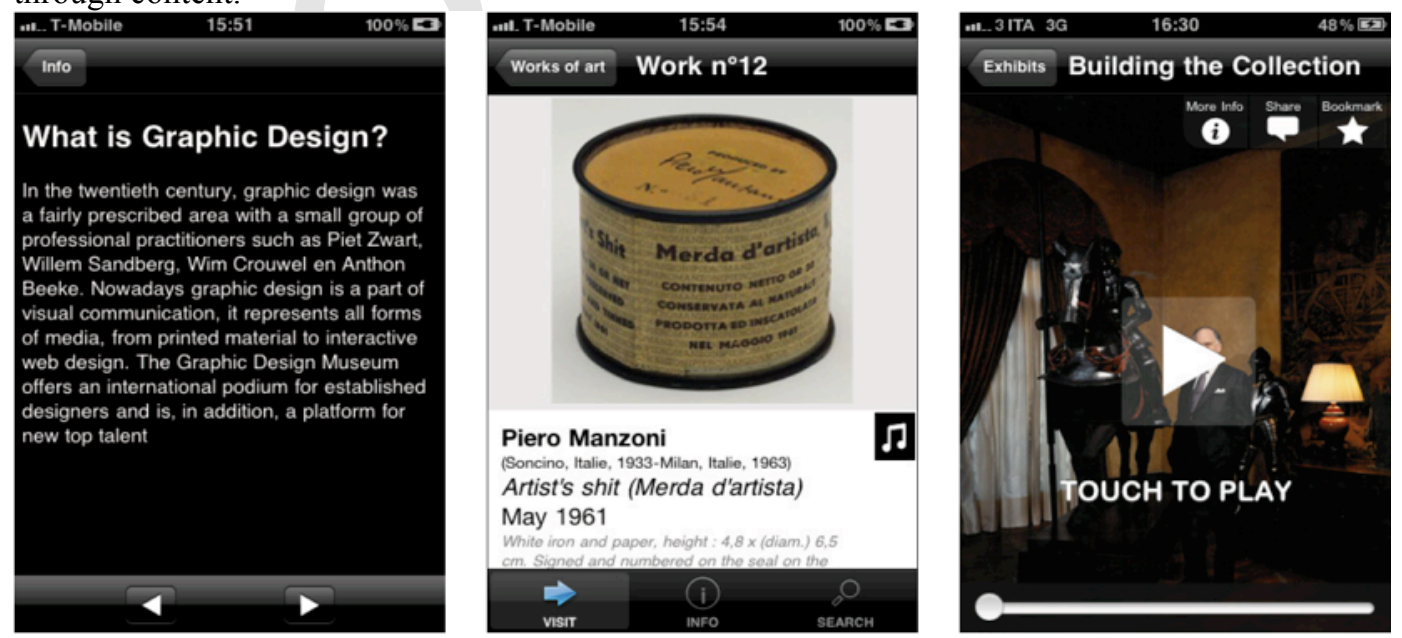

Fig. 11 (from the top left) Textual description, GDM iPhone app; Text and image description, CPMetz app; video, Lauder Collection app. 

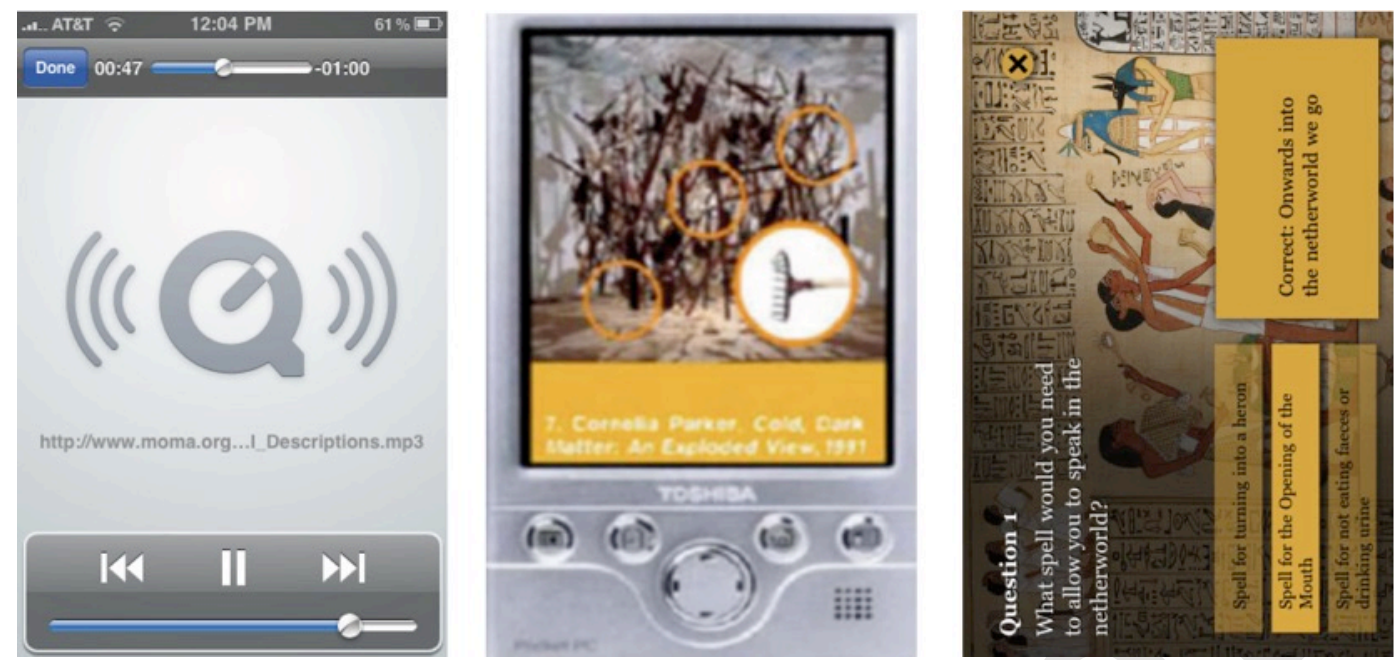

Fig. 12 (from the top left) Audio, MoMa web-based app; interactive image, Multimedia Tour at Tate Modern; interactive mobile interface with questions, The Book of Dead app, British Museum.

\section{Providing Content Personalization}

It clearly emerges from several dimensions presented in this paper that the way visitors interact with content gives them more freedom of choice. Mobile communication has shifted from a rigid linear tour, organized for guiding visitors through a pre-established museum route, to a "nonlinear" way of experiencing the museum. While the former offers an experience comparable to an "audio documentary" with very little possibility of interaction because visitors cannot choose among different types of content, the latter is a more "enriched" and "flexible" tour.

Visitors can also choose tours of the highlights of the gallery's collection by selecting one of several themes. Visitors should have the possibility of filtering and selecting content according to his/her needs and demands by, for instance, choosing content thematically by artist, historical period, the highlights of the gallery's collection, and so forth. The same content can be dynamically organized according to one or more parameters set by the visitors themselves (fig. 13)
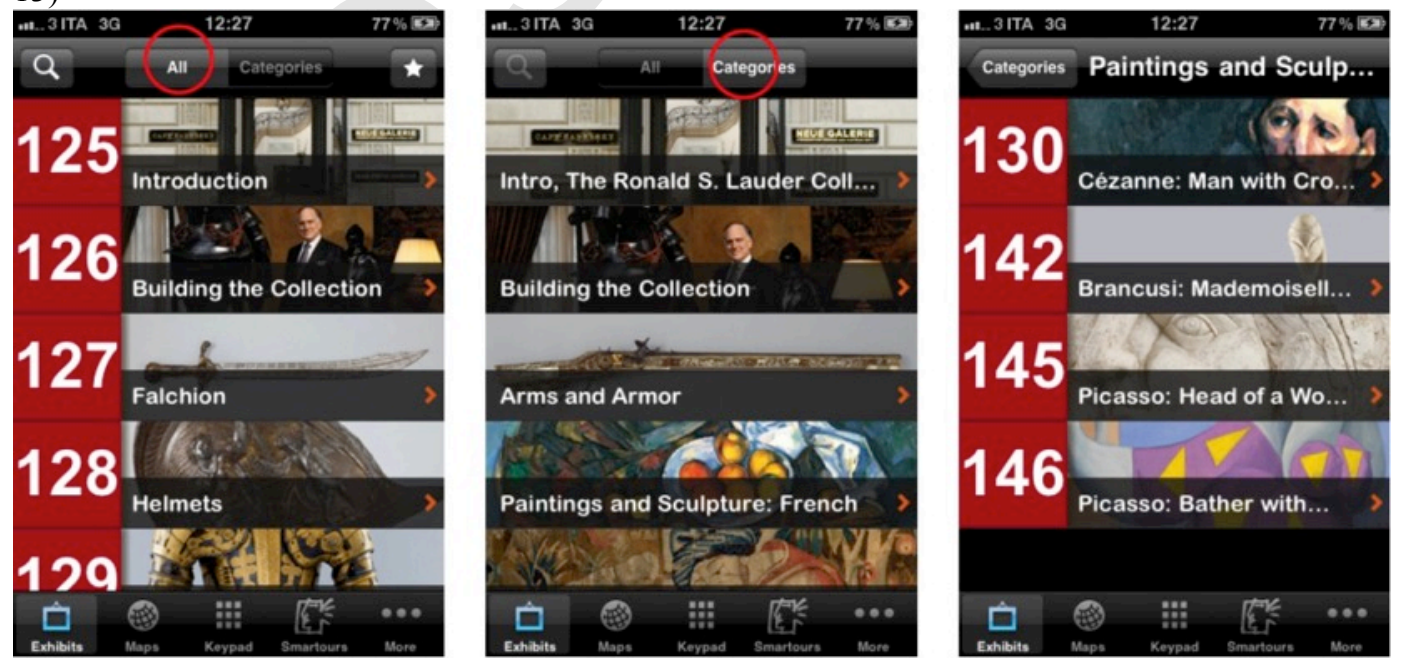

Figure 13 - Lauder Collection at Neue Galerie New York - Acoustiguide Smartour iPhone app

Cutting-edge mobile apps may enhance visitors' museum experiences in a very personalized, intensive and engaging way inside the museum. For instance, the AMNH Explorer app (fig. 14) 
allows visitors to plan their own tour before they arrive at the museum itself. The AMNH Explorer app offers one hundred pre-loaded exhibits which visitors can choose from in order to create and then take the tour that best meets their needs and expectations.
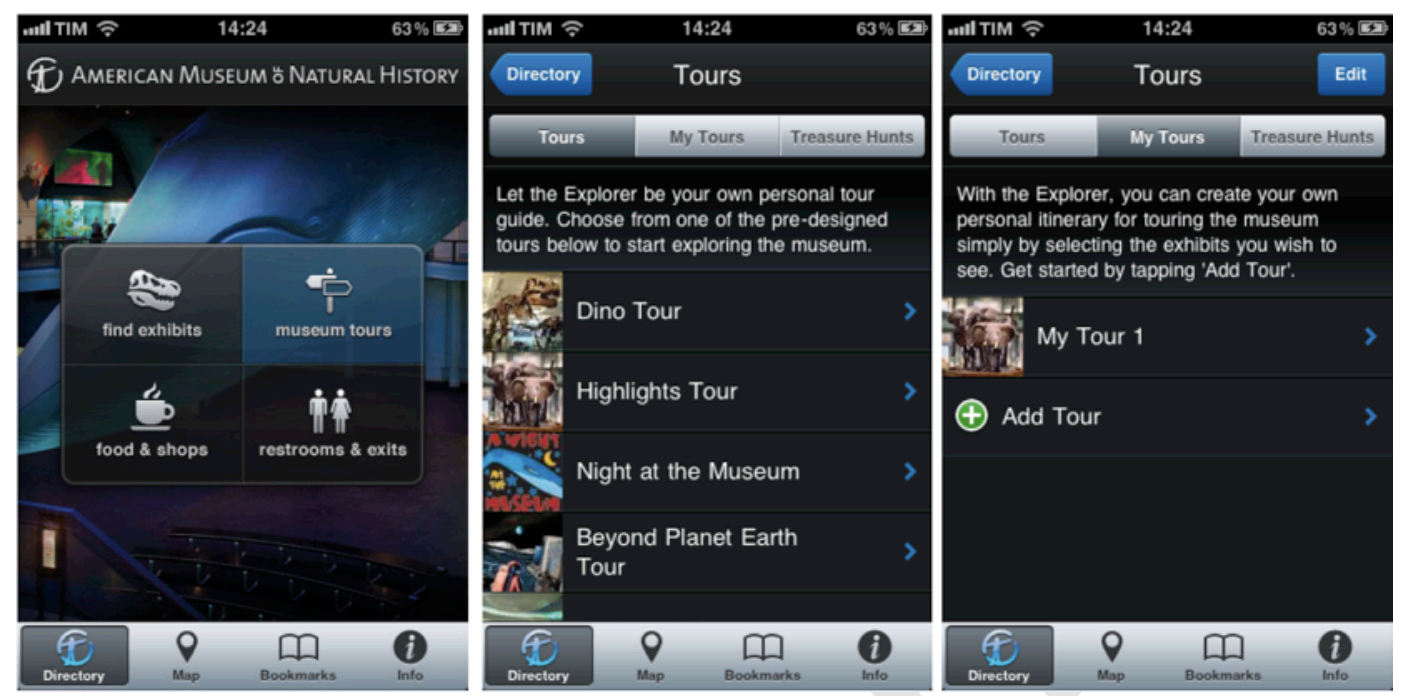

Fig. 14 - Screenshots of the AMNH Explorer iPhone app by American Museum of Natural History. New York, USA

\section{The Threshold is All-Important}

Mobile app designers have to carefully evaluate the point (threshold) at which the unconfident visitor might turn away. One main challenge in designing an interface and its content is to find the balance between a very trivial (banal) design and the "fear threshold." Going to either extreme is a bad approach since the former makes the experience too simplistic and insufficiently engaging, while the latter intimidates the visitor because it might be too complicated.

For visitors, cognitive load varies according to its level of sensory and informational content. The target audience and individuals all have different thresholds, so balancing both the sensory and informational loads is crucial in the mobile apps. The "sensory load" is for the most part visual and auditory. As discussed above, the design of interface components plays a crucial role for determining the sensory load of visitors who use mobile devices.

With regard to the "informational load" it is essential to consider both the quality and quantity of content. For example, a highly educated visitor might appreciate and be engaged by complex information (because it is more interesting than simple information), while the average tourist is not always willing to face the same difficulty. Also in this case, a careful study of visitors will be crucial to understand how to balance out their needs and design the "right" mobile interpretation that fits the expectations and needs of a specific target.

\section{Visitors Require Good Content}

Museum content is a fundamental part of the mobile experience (Fantoni, 2008). The quality of the content presented strongly determines the quality of the mobile visitor experience. What makes for good content? And how can it be fitted to new mobile media? 
During an online conference on mobile media for museums, content-writer Sandy Goldberg took a quick survey of the conference attendees ${ }^{7}$ by asking them what makes for good content (fig. 15).

What makes good content? - choose up to 2 of these:
$\square$ It offers a lot of information
$\square$ It surprises me
$\square$ It's emotionally resonant/memorable
$\square$ It makes me think in a new way
$\square$ It gives context to an object/display
$\square$ It's clear and concise
$\square$ Other (elaborate in Chat)

Fig. 15 - This screen shot is a quick survey of the conference attendees (about 700) whom the content-writer Sandy Goldberg asked what makes for good content (for them).

It is particularly interesting to note how the results showed that the idea of "good content" depends mainly on the way the experience affects one's emotions and memory. For mobile apps, this means that they must be highly engaging. Designers must consider how to make meaningful mobile content from the "story" of the content narrative while also including various kinds of digital messages generated by different sources (curators, educators, artists, restorers, and so on).

From the direct analysis of several projects, the fact has emerged that mobile apps for museums may adopt a host of source material into the informational content to be conveyed. The source materials span from visitor comments to expert interpretations (fig. 16, 17). Interviews with curators can enlighten the visitor on the room or exhibit as a whole, while expert and artists provide proper content and a different point of view. It is important that interviews with a curator, artist or other expert have an accessible, friendly tone in order to engage visitors. Another source for material is the visitors themselves. Through comments, votes on polls, and social media, visitors are able to add personal stories, points of view, and emotions about the object on display. They also can share their thoughts through "vox pops," interviews that contribute content worth communicating. Sounds themselves can be very engaging, especially when they reproduces the sound of the environment where the object on display was originally placed or created.
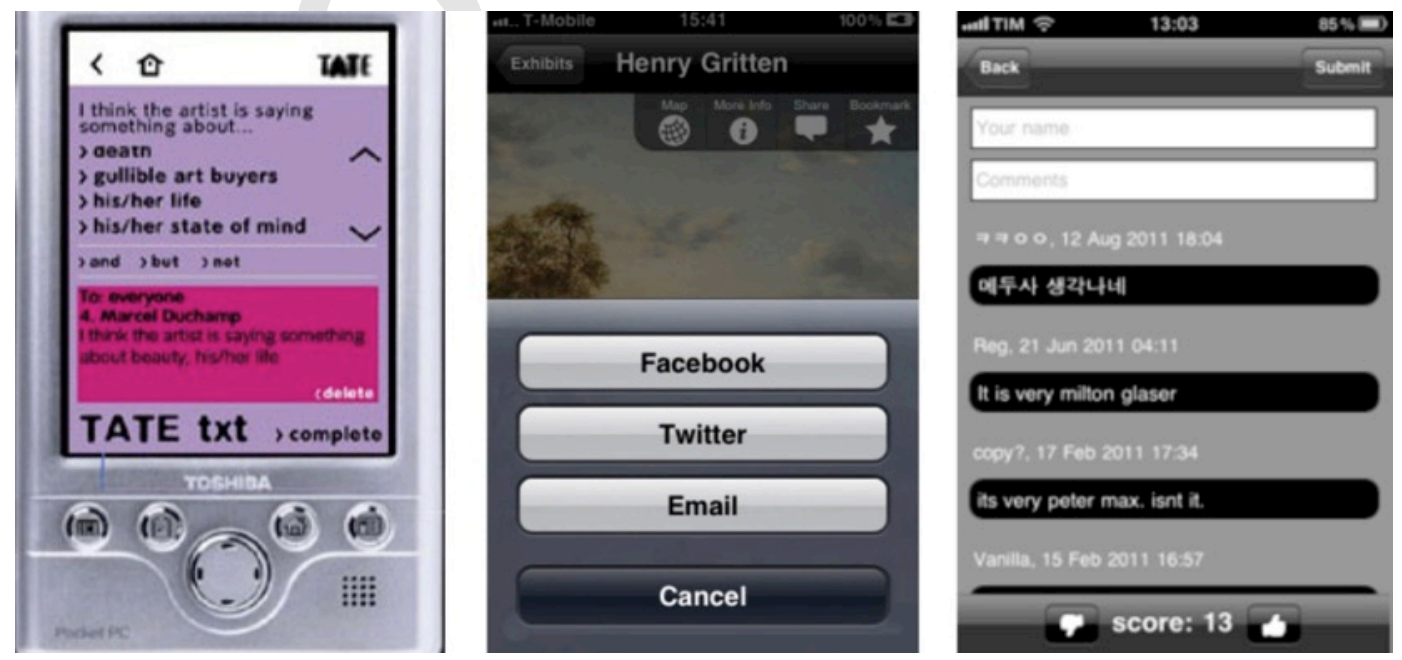

\footnotetext{
7 "Second Museum \& Mobile" online conference, 22 March 2011, section 2: S. Goldberg, Developing Mobile Experiences \& Content.
} 
Fig. 16 - (from the right) Tate Modern Multimedia Tour; AD2 iPhone apps; GDM iPhone app, Graphic Design Museum in Breda.

An example of the application of different contents in a single mobile app comes from Proctor, who defines the variety of contents present in each node with the term "soundbite" (fig. 17). According to Proctor:

"Soundbites are the curated 'stops' or nuggets of information on specific objects or exhibits. [...] Since there is no such thing as one-size-fits-all interpretation, stops should be layered, and ideally enable access to a variety of types of content to satisfy different kinds of questions and learning styles: not just audio and video clips, but wall labels, catalogue text, interactives, and user-generated content too. [...] In theory, soundbites are like atoms that can be searched and combined with other stops in a variety of ways to build new insights and bodies of information around a given topic [...]" (Proctor, 2010)

The idea of "soundbite" is a key principle for formulating an effective mobile-based digital content and interpretation strategy. In substance, what is more, designing engaging content means effectively integrating different mobile-based messages into the museum tour experience.
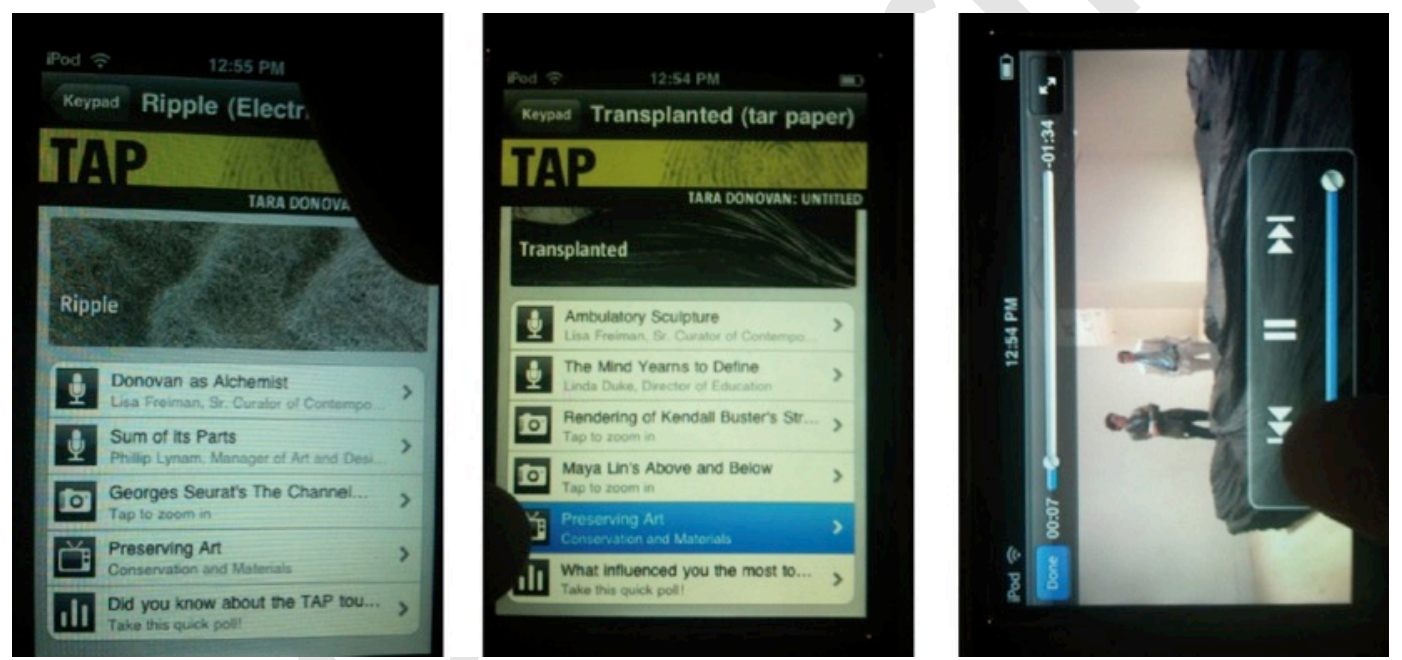

Fig. 17 -TAP iPhone and iPod app. Indianapolis Museum of Art. The pictures (taken by the author on May 2010) show two soundbites related to two art-works made by the artist Tara Donovan (Transplanted and Ripple). The third picture (the video) is a video interview with museum experts of "conservation and materials".

\section{Visitors Active Participation}

"Active participation does not necessarily mean pulling levers or pressing buttons" (Black, 2005). It is also important to involve visitors intellectually ("mind-on" and not only "hands-on"). For this reason, when creating a mobile app, designers must carefully consider that visitors learn by a mixture of (inter)actions: doing, thinking, watching, reading, listening, imagining, socially interacting, interacting with the object (when possible), commenting on objects or on the exhibit, discussing, and assimilating ${ }^{8}$. As previously described, learning by a mobile media occurs as a result of visitor participation.

\footnotetext{
${ }^{8}$ For more in depth investigation on "visitor active participation" see Simon, Nina. Participatory Museums. Museum 2.0: Santa Cruz, CA, 2010.
} 
Proctor (2010) offers one of the most interesting studies about how content should be structured in order to guarantee effective mobile interpretation. She highlights the great potential that the "liminal space" between "stops" might offer to enhance participation and, therefore, the visitor experience. Unlike traditional audio guides, in which tours are rigid and linear, new mobile media incorporate challenges to the visitors into the tour. With these challenges, visitors will be able to receive additional information, play games, complete tasks, or simply devote time to sharing impressions with a companion, so that the "liminal spaces" become an opportunity for an audience's participation (Proctor, 2010).

An example of this concept is "soundtrack," a term that Nancy Proctor uses to define a variant of the idea of the "rigidity" and monotony of the traditional linear audio tour:

"A variant on the original linear audio tour, the 'soundtrack' provides tools for understanding key principles of the displays. It helps me avoid being blinded to the forest by the trees. When I walk into an exhibition space, the first thing I need may not be to know when that painter was born and died; I probably need some conceptual orientation: where am I? What's going on here? Why is all this stuff in this one place? What am I supposed to be taking away from it? [...] Ideally, the soundtrack is a story or a conversation that the visitor can join. It can be a rich narrative in which the visitors immerse themselves, or a dialogue that opens up a space for the visitor to join the conversation and form his or her own opinions. [...]" (Proctor, 2010)

As an aid for readers, I shall sum up Proctor's concept through a visual representation aimed at providing a uniform vision of the concepts under discussion, giving a concrete example of a mobile app (fig. 18a, 18b, 19).
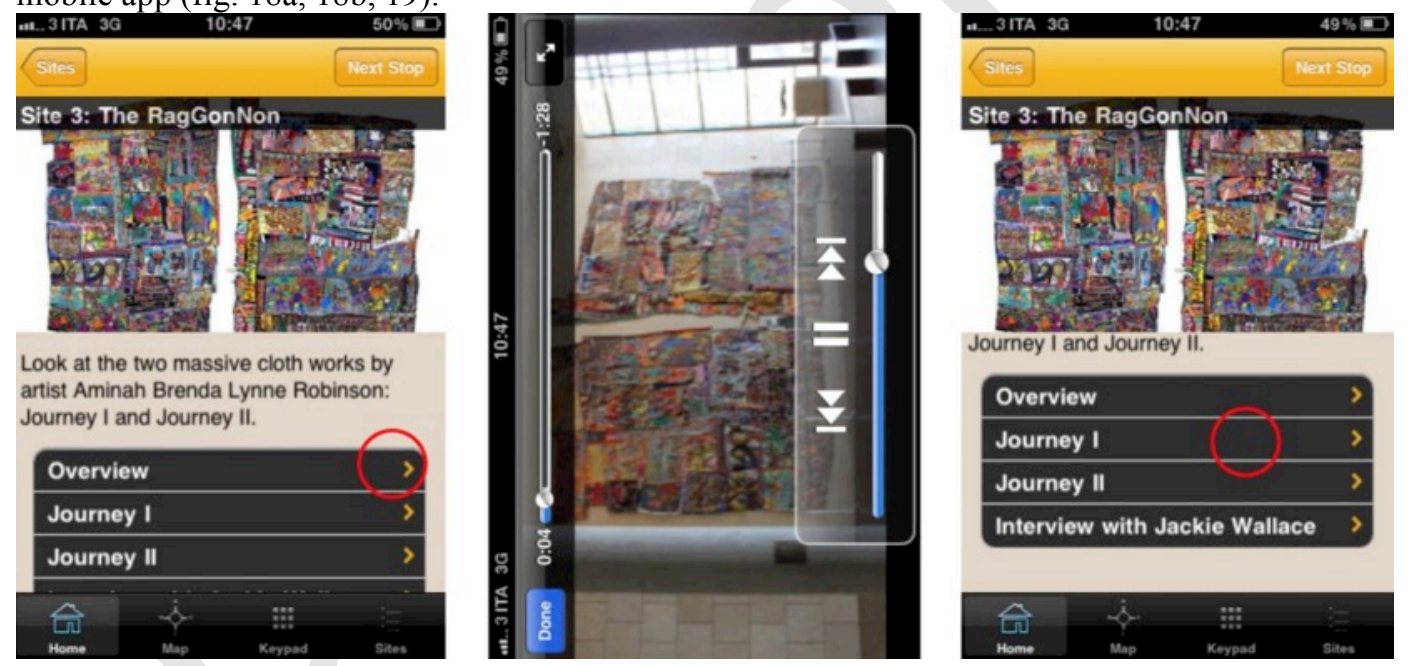

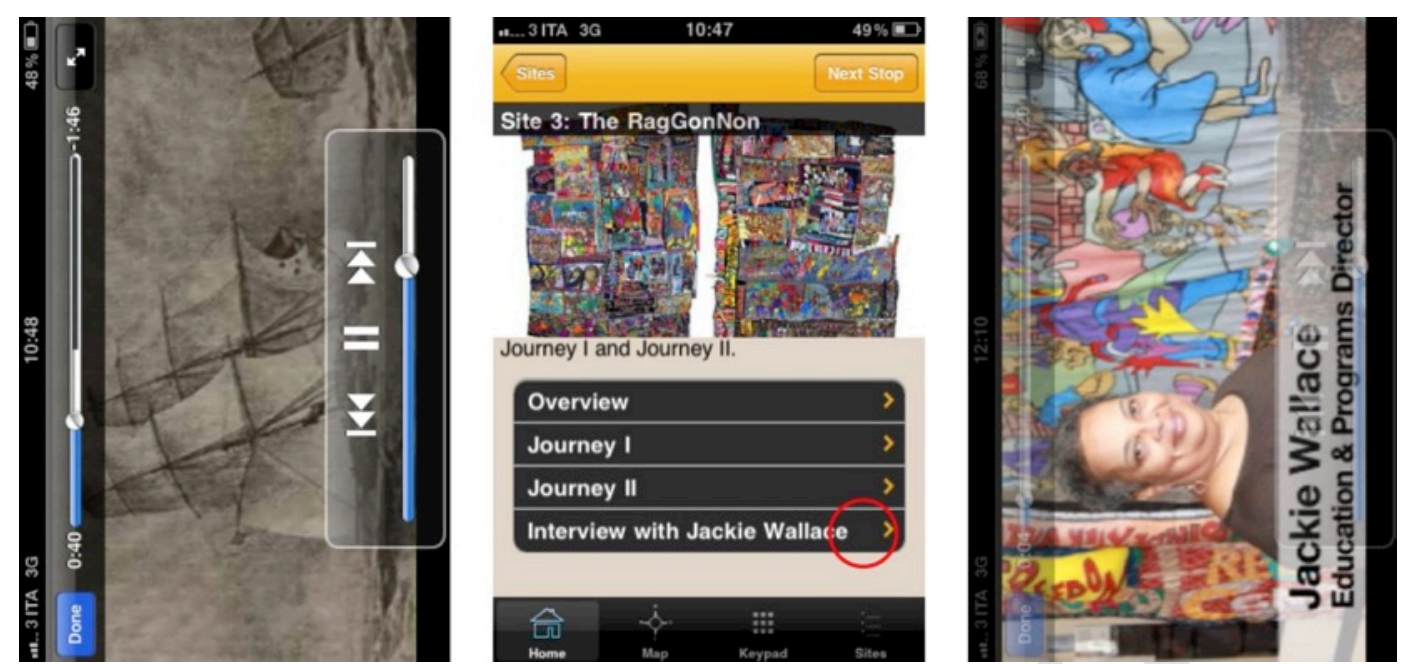

Fig. 18a,b-Example of soundtracks: Freedom iPhone app.

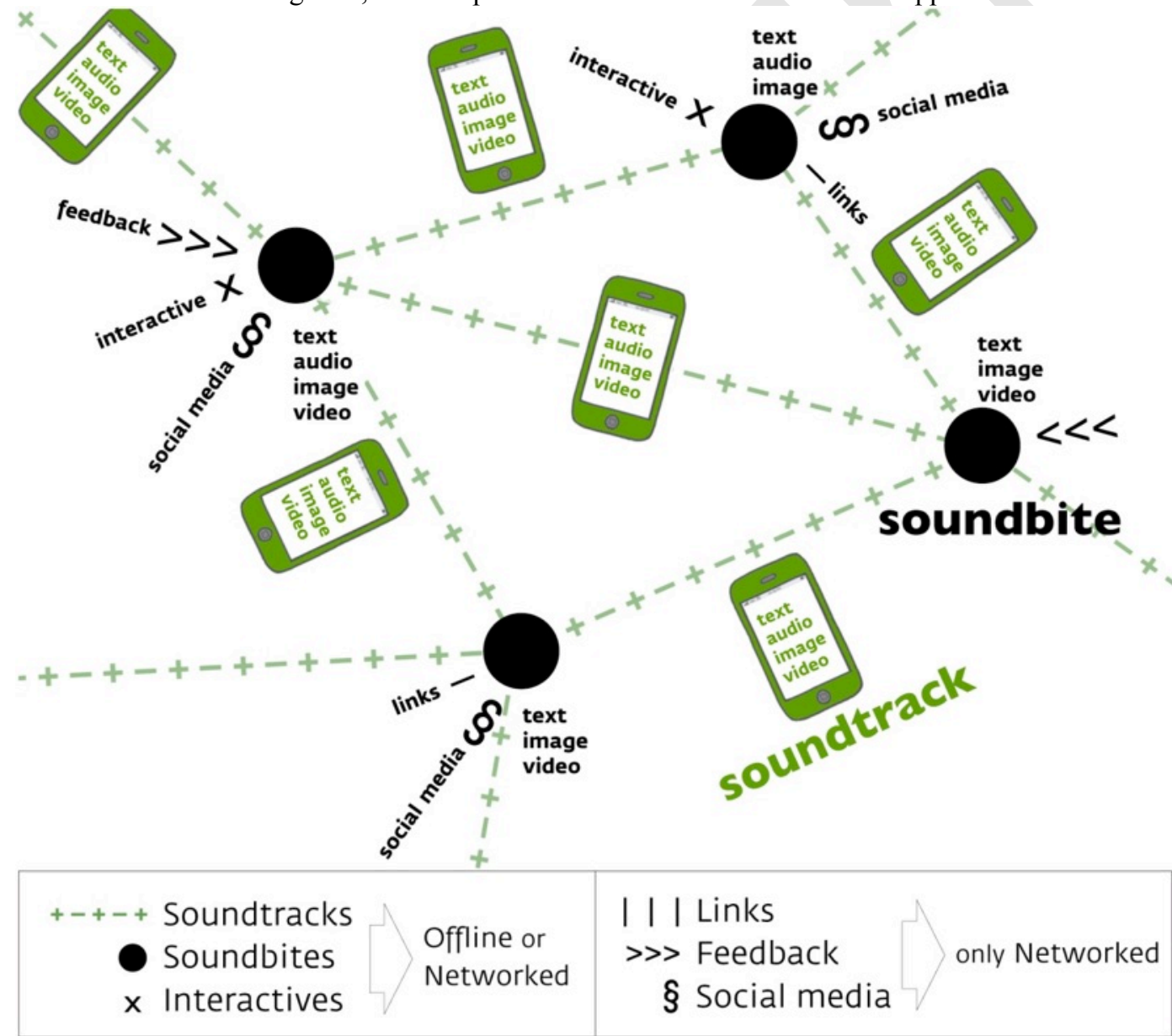

Figure 19 - Visual representation of the concept of soundtracks.

Source: diagram created by Marco Mason (copyright) 
Mobile device technical features enable visitors to directly participate in the creation of content through picture-taking, video-recording, comments, and content-sharing with other visitors who are present both onsite and remotely. For example, smartphones such as the iPhone allow still and video camera features to be integrated into an app, allowing visitors to take and share pictures or videos (fig. 20).
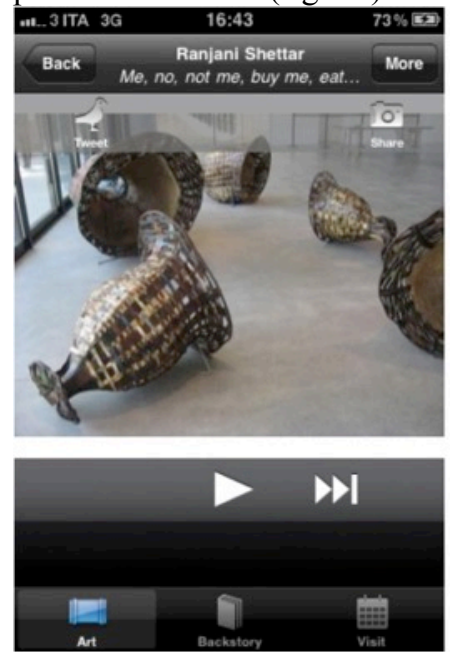

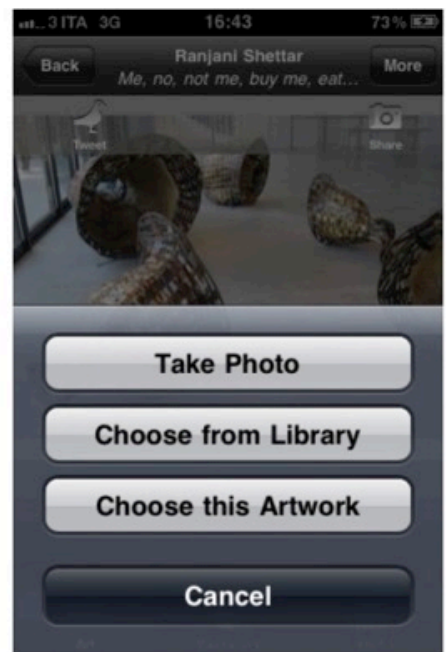

Fig. 20 - SFMoMa Rooftop iPhone app.

As a result, more and more museums in the last few years have made use of social media sites such as Flickr, Facebook, and Twitter. They also use blogs to incorporate user-generated content into their websites, and designers of mobile apps for museums have started to consider this form of content generation to be an excellent method for involving visitors. Museum professionals and designers are imagining and experimenting with different strategies for stimulating and evoking responses from visitors and then incorporating these responses into the interactive modalities of both their mobile designs and the museum's broader communications networks.

User-generated content gives visitors the opportunity to foster their creativity and personal expression by generating, an audio-, text-, or image-based response to the museum visit (fig. 21).
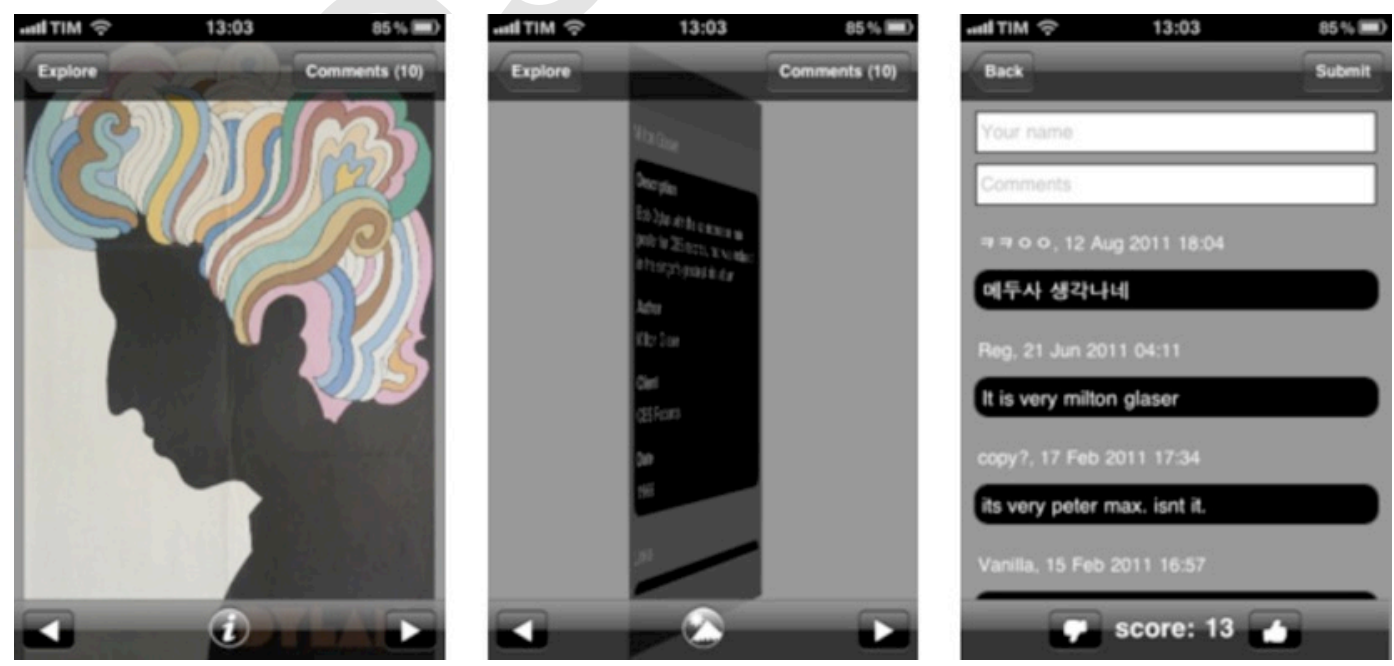

Fig. 21 - Visitor feedback. GDM iPhone app, Graphic Design Museum in Breda

\section{Conclusion}


In this paper we have described the fundamental "dimensions of the context" of mobile-media enhance visitor experience. They rise from three main domains on which the design of mobile media moves: museum, visitors, and technological. Each of these domains molds a visitor's experience at a museum.

Through the investigation of museum-, visitor-, and mobile technology-related fields, we have come to a better understanding of the fundamental "dimensions" the design is meant to address. What has emerged from the investigation of the three domains is the complexity of such mobile media systems.

This effort became significant for designers since it can enable to make more informed design decisions. There are many "dimensions" to consider when creating any mobile app. Technological factors such as small displays affect interactions between the visitor, the device, and the museum space. In turn, interactions strongly influence the structure and form of the mobile interface. Museum factors that concern the museum mission change how they pursue interpretation goals. Visitor factors pay great attention to the needs, expectations and behaviors of visitors, which, in turn, strongly affects decisions about content and active participation.

Understanding "dimensions of context" is an important first step in any design process based on a human-cantered design approach since it allows designers to consider (and integrate) any aspect of the visitor experience in the design of a mobile app.

\section{Acknowledgements}

Marco Mason is a Marie Curie Fellow. He is conducting a three years research project funded by the European Union - Marie Curie Actions International Outgoing Fellowships for Career Development (IOFs). The outgoing stage of the fellowship (2013-14) takes place at the Massachusetts Institute of Technology supervised by Prof. John Durant from the Science, Technology and Society Program; (2013-14) and the return stage (2015) will take place at the University of Leicester supervised by Dr. Giasemi Vavoula from the School of Museum Studies. 


\section{REFERENCES}

Barry Ailsa. "Creating A Virtuous Circle Between A Museum's On-line And Physical Spaces." In Museums and the Web 2006: Proceedings, edited by J. Trant and D. Bearman. Toronto: Archives \& Museum Informatics, 2006.

Black, Graham. The Engaging Museum: Developing Museums for Visitor Involvement (Heritage: Care-Preservation-Management). New York: Routledge, 2005.

Brown, Tim. Change by Design: How Design Thinking Can Transform Organizations and Inspire Innovation. New York: Collins Business, 2009

Caplan, Ralph. By Design Why There Are No Locks on the Bathroom Doors in the Hotel Louis Xiv and Other Object Lessons. Fairchild Publications, 2004.

Cooper, Alan, Reimann, Robert, and Dave Cronin. About Face 3: The Essentials of Interaction Design. [3rd ed.], Completely rev. \& updated. Indianapolis: Wiley Publisher, 2007.

Fantoni, Silvia. "Mobile Multimedia: Reflections From Ten Years of Practice." In Digital Technologies and the Museum Experience: Handheld Guides and Other Media, edited by Loïc Tallon, and Kevin Walker, 79 - 96. AltaMira Press, 2008.

Fantoni, Silvia, et al. "Mobile devices for orientation and way finding: the case of the British Museum multimedia guide." In Museums and the Web 2011: Proceedings, edited by J. Trant and D. Bearman. Toronto: Archives \& Museum Informatics, 2011.

Forbes, Ted. "Native or Not? Why a Mobile Web App Might Bde Right for Your Museum." In Mobile Apps for Museums: The AAM Guide to Planning and Strategy, edited by Nancy Proctor. American Association of Museums, 2011.

Hassenzahl, Marc. Experience Design: Technology for All the Right Reasons (Synthesis Lectures on Human-Centered Informatics). Morgan and Claypool Publishers, 2010.

Hooper-Greenhill, Eilean. Museums and the Interpretation of Visual Culture (Museum Meanings). Routledge, 2000.

Kuniavsky, Mike. Smart things : ubiquitous computing user experience design. Amsterdam: Morgan Kaufmann Publisher, 2010

Leon, S., Brennan, S., Lester, D., Odiorne, A. Mobile for Museums (Report), 2009. At http://chnm.gmu.edu/labs/mobile-for-museums.

Preece, Jenny, Yvonne Rogers, and Helen Sharp. Interaction Design: Beyond Human-Computer Interaction. [3rd Ed]. Wiley, 2011.

Proctor, Nancy. "Mobile Social Media in the Museum as Distributed Network." In Interactive Museums: Digital Interpretation and Online Experiences, 1-21. Museum Identity Ltd., $2011 \mathrm{a}$.

Proctor, Nancy. Mobile Apps for Museums: The AAM Guide to Planning and Strategy. American Association of Museums, 2011b.

Proctor, Nancy. "The Museum is Mobile: Cross-Platform Content Design for Audiences on the Go." In Museums and the Web 2010: Proceedings, edited by J. Trant and D. Bearman. Toronto: Archives \& Museum Informatics, 2010.

Samis, P. "Visual Velcro: Hooking the Visitor." Museum News 86, no. 6 (2007): 57-62.

Smith, Koven. "The Future of Mobile Interpretation." In Museums and the Web 2010: Proceedings, edited by J. Trant and D. Bearman. Toronto: Archives \& Museum Informatics, 2010.

Stein, Robert. "Mobile Content Strategies for Content Sharing and Long-Term Sustainability." In Mobile Apps for Museums: The Aam Guide to Planning and Strategy, edited by Nancy Proctor. American Association of Museums, 2011.

Tallon, Loic, Walker, Kevin. "The Iphone Effect? Comparing Visitors' and Museum Professionals' Evolving Expectations of Mobile Interpretation Tools." In Museums and the Web 2010: Proceedings, edited by J. Trant and D. Bearman. Toronto: Archives \& Museum Informatics, 2010.

Tallon, Loic, Froes, Isabel. "Going Mobile? Insights Into the Museum Community's Perspectives on Mobile Interpretation." In Museums and the Web 2011: Proceedings, edited by J. Trant and D. Bearman. Toronto: Archives \& Museum Informatics, 2011. 
Wigelius and Väätäjä. "Dimensions of context affecting user experience in mobile work." In INTERACT '09 Proceedings of the 12th IFIP TC 13 International Conference on Human-Computer Interaction: Part II. 604-618. Springer-Verlag Berlin, 2009.

\section{ABOUT THE AUTHOR}

Dr. Marco Mason: Marco Mason has a PhD in Design Science. Since 2003 he has carried on activities of research and teaching in the field of digital media design for heritage. He has recently won a Marie Curie Fellowship for a Design Research project that aims to investigate design theory and practices of digital media for heritage. He is carrying on the Design Research project at the School of Museum Studies (University of Leicester, UK) and the Program in Science, Technology, and Society (Massachusetts Institute of Technology, USA). 